\title{
Correlations of the Specific Rates of Solvolysis of Aromatic Carbamoyl Chlorides, Chloroformates, Chlorothionoformates, and Chlorodithioformates Revisited
}

\author{
Dennis N. Kevill ${ }^{1, *}$, Fumie Koyoshi ${ }^{2}$ and Malcolm J. D'Souza ${ }^{2, *}$
}

1 Department of Chemistry and Biochemistry, Northern Illinois University, DeKalb, Illinois 601152862, USA; E-mail: dkevill@niu.edu

2 Department of Chemistry, Wesley College, 120 N. State Street, Dover, Delaware 19901-3875, USA; E-mail: DSouzaMa@Wesley.edu

* Authors to whom correspondence should be addressed.

Received: 22 March 2007 / Accepted: 24 April 2007 / Published: 30 April 2007

\begin{abstract}
Additional specific rates of solvolysis are determined for phenyl chloroformate. These values are combined with literature values to give a total of 49 data points, which are used within simple and extended Grunwald-Winstein treatments. Literature values are also brought together to allow treatments in more solvents than previously for three $\underline{\mathrm{N}}$-aryl-프methylcarbamoyl chlorides, phenyl chlorothionoformate, phenyl chlorodithioformate, and $\underline{\mathrm{N}}, \underline{\mathrm{N}}$-diphenylcarbamoyl chloride. For the last two listed, moderately strong evidence for a meaningful inclusion of a term governed by the aromatic ring parameter (I) was indicated. No evidence was found requiring inclusion of this parameter for ionization reactions with only one aromatic ring on the nitrogen of carbamoyl chlorides or for the solvolyses of the chloroformate or chlorothionoformate proceeding by an addition-elimination (associationdissociation) mechanism.
\end{abstract}

Keywords: solvolysis, carbamoyl chlorides, chloroformates, chlorothionoformates, chlorodithioformates, Grunwald-Winstein equation, aromatic ring parameter (I). 


\section{Introduction}

The Grunwald-Winstein equation (equation 1) was developed [1] in 1948 for the correlation of

$$
\log \underline{\mathrm{k}} / \underline{\mathrm{k}}_{0}=\underline{\mathrm{mY}}+\underline{\mathrm{c}}
$$

specific rates of solvolysis of reactions which proceed via a rate-determining ionization $\left(\mathrm{S}_{\mathrm{N}} 1+\mathrm{E} 1\right)$. The original standard substrate, tert-butyl chloride, has been replaced by 1-adamantyl chloride [2] and either 1- or 2- adamantyl derivatives have been used to set up a series of $\underline{Y}_{X}$ scales for the X leaving group [3]. Since, with both substrates, a double bond would develop at the bridgehead, which is energetically disfavored (Bredt's Rule), only substitution reaction is observed. In equation $1, \underline{\mathrm{k}}$ and $\underline{\mathrm{k}}_{\mathrm{o}}$ represent the specific rates of solvolysis in the solvent under consideration and in an arbitrarily chosen [1] standard solvent (80\% ethanol), $\underline{m}$ represents the sensitivity to changes in the solvent ionizing power value $(\underline{\mathrm{Y}})$, and $\underline{\mathrm{c}}$ is a constant (residual) term.

It was realized that equation 1 could not be expected to apply to solvolyses where the solvent also participates in the rate-determining step of a bimolecular process $\left(\mathrm{S}_{\mathrm{N}} 2+\mathrm{E} 2\right)$ and it was proposed [4] that an additional term governed by the sensitivity $(\underline{\ell})$ to changes in solvent nucleophilicity $(\underline{N})[5,6]$ should be added (equation 2).

$$
\log \underline{\mathrm{k}} / \underline{\mathrm{k}}_{0}=\underline{\ell \mathrm{N}}+\underline{\mathrm{mY}}+\underline{\mathrm{c}}
$$

Since for the commonly used solvents, such as aqueous ethanol, methanol, or acetone, the $\underline{N}$ values tend to the increase in a fairly uniform manner as the $\underline{Y}$ values decreases [7], multicollinearity can be a major problem if solvents are restricted to these classes. Fortunately, commercially available fluoroalcohols [2,2,2-trifluoroethanol (TFE) and 1,1,1,3,3,3-hexafluoro-2-propanol (HFIP)] in varying proportions with water show very different relationships between $\underline{N}$ and $\underline{Y}$ values [8, 9] decrease. These fluoroalcohol-containing solvents play an important role in studies designed to allow a meaningful application of equation 2.

For reactions in which an aromatic ring is attached to the site of developing charge, dispersion in simple (equation 1) plots is often observed independent of any dispersion that might arise due to nucleophilic solvation effects [10-13]. This can be treated by the development of similarity models, using similarly constituted standard substrates to develop new ionizing power scales [14, 15]. This is, however, very labor intensive and a new scale must be developed based not only on each leaving group but also on the number of aromatic rings entering into conjugation with the developing positive charge [16]. We have favored an alternative approach [10-13] in which one can continue to use an established $\underline{Y}_{X}$ scale [3], accompanied by the introduction of a term governed by the sensitivity (h) to solventinduced changes in an aromatic-ring parameter ( $\underline{\mathrm{I}})$, as shown in equation 3 . The $\underline{\mathrm{I}}$ parameter is independent of the leaving group and, indeed, it can be applied to solvolyses involving both anionic [11-13] and neutral [17] leaving groups. It can also be applied to solvolyses in which an aryl group

$$
\log \underline{\mathrm{k}} / \underline{\mathrm{k}}_{0}=\underline{\ell \mathrm{N}}+\underline{\mathrm{mY}}+\underline{\mathrm{hI}}+\underline{\mathrm{c}}
$$

migrates from the $\beta$ - to the $\alpha$-carbon (1,2-aryl shift) [18]. In many application of the $\underline{\text { II }}$ term, the nucleophilic solution contribution is negligible $(\ell \approx 0)$ and equation 4 can be applied [18]. 


$$
\log \underline{\mathrm{k}} / \underline{\mathrm{k}}_{0}=\underline{\mathrm{mY}}+\underline{\mathrm{hI}}
$$

We have carried out studies to examine the extent to which the $\underline{Y}$ and $\underline{N}$ scales developed for solvolytic substitution (sometimes accompanied by elimination) reaction to an $\mathrm{sp}^{3}$ hybridized carbon can be applied to substitution at an acyl ( $\mathrm{sp}^{2}$-hybridized) carbon as in acyl halides $[19,20]$, haloformate esters [21-26], and carbamoyl chlorides [27-29], and to displacement of chloride ion from sulfur or phosphorus during solvolyses of organosulfur [8] and organophosphorus [30, 31] substrates.

Our application of equation 2 to solvolyses at $\mathrm{sp}^{2}$-carbon has been followed by related studies in other laboratories. Usually these studies have included an extension to additional solvents. A reassessment of these solvolyses in all the solvents now available allows for a more thorough correlation analysis and the possibility of probing as to how robust the analyses are in terms of whether the initially reported sensitivities ( $\underline{\ell}$ and $\underline{m}$ ) change appreciably on the incorporation of new data points. In one instance, new substrates, closely related to the earlier one, have been studied, allowing one to see the effect on the $\underline{\ell}$ and $\underline{m}$ values of the structural variation.

In our earlier studies, we assumed that there was no appreciable transfer of charge to aryl groups present on the nitrogen of carbamoyl chlorides or within the aryloxy group of chloroformate esters. Accordingly, we did not consider it necessary to include the $\underline{h \mathrm{I}}$ term and the correlations were only in terms of equations 1 and 2. This belief was based upon the absence of canonical resonance structures which could transfer developing positive charge to the aromatic ring. In his study of the solvolyses of

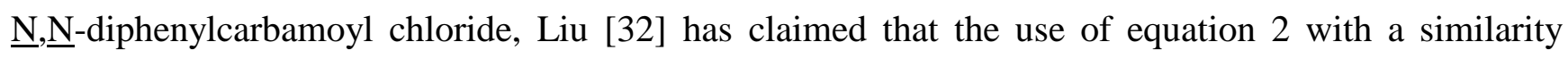
model based $\underline{Y}$ scale $\left(\underline{Y}_{\mathrm{BnCl}}\right)$ [15] suggests a non-canonical resonance, which can lead to the transfer of a large amount of the developing positive charge to the phenyl rings. Further, he claims that this transfer is supported by quantum calculations.

If such a non-canonical transfer is possible with an intervening nitrogen, presumably it will also be possible with an intervening oxygen or sulfur. Accordingly, we have decided to reinvestigate and extend the correlations of the solvolyses of arylmethylcarbamoyl chlorides (ArMeNCOCl, 1), diphenylcarbamoyl chloride $\left(\mathrm{Ph}_{2} \mathrm{NCOCl}, 2\right)$, phenyl chloroformates (PhOCOCl, 3), phenyl chlorothionoformate $(\mathrm{PhOCSCl}, \mathbf{4})$ and phenyl chlorodithioformate $(\mathrm{PhSCSCl}, \mathbf{5})$ using all of the data presently available.

We have used the $\underline{N}_{T}$ values, based on solvolyses of the $\underline{S}$-methyldibenzothiophenium ion $[6,33]$ as the solvent nucleophilicity scale, in conjunction with $\underline{Y}_{\mathrm{Cl}}$ values based on the solvolyses of 1adamantyl chloride [2, 3, 34], and $\underline{I}$ value based on the specific rates of solvolysis of the $\underline{p}$ methoxybenzyldimethylsulfonuim ion relative to those of the 1-adamantyldimethylsulfonium ion [10, $35]$. 


\section{Results and Discussion}

\subsection{Solvolyses of N-Aryl-N-Methylcarbamoyl Chlorides.}

We have previously studied [29] the solvolyses of the parent $\underline{N}$-methyl-N-phenylcarbamoyl chloride in 19 solvents at $62.5^{\circ} \mathrm{C}$. The analysis in terms of equations 2 and 3 were presented and these, together with the correlation in terms of equation 1 , are reported within Table 1 . More recently, a study has been made, at $25.0^{\circ} \mathrm{C}$, not only of the parent compound but also of the p-chloro- and p-nitro-derivatives [36]. The value reported for the parent in $80 \%$ ethanol of $3.27 \times 10^{-6} \mathrm{~s}^{-1}$ was in good agreement with a value of 3.37( \pm 0.14$) \times 10^{-6} \mathrm{~s}^{-1}$ obtained earlier [29]. Up to three TFE-water solvents were utilized, with the solvents prepared on a volume-volume basis. We have converted the $\mathrm{TFE}-\mathrm{H}_{2} \mathrm{O}$ solvents to weightweight compositions and then obtained the required $\underline{\mathrm{N}}_{\mathrm{T}}, \underline{\mathrm{Y}}_{\mathrm{Cl}}$, and I values by interpolation within plots of the literature values, which are tabulated for a series of weight-weight compositions.
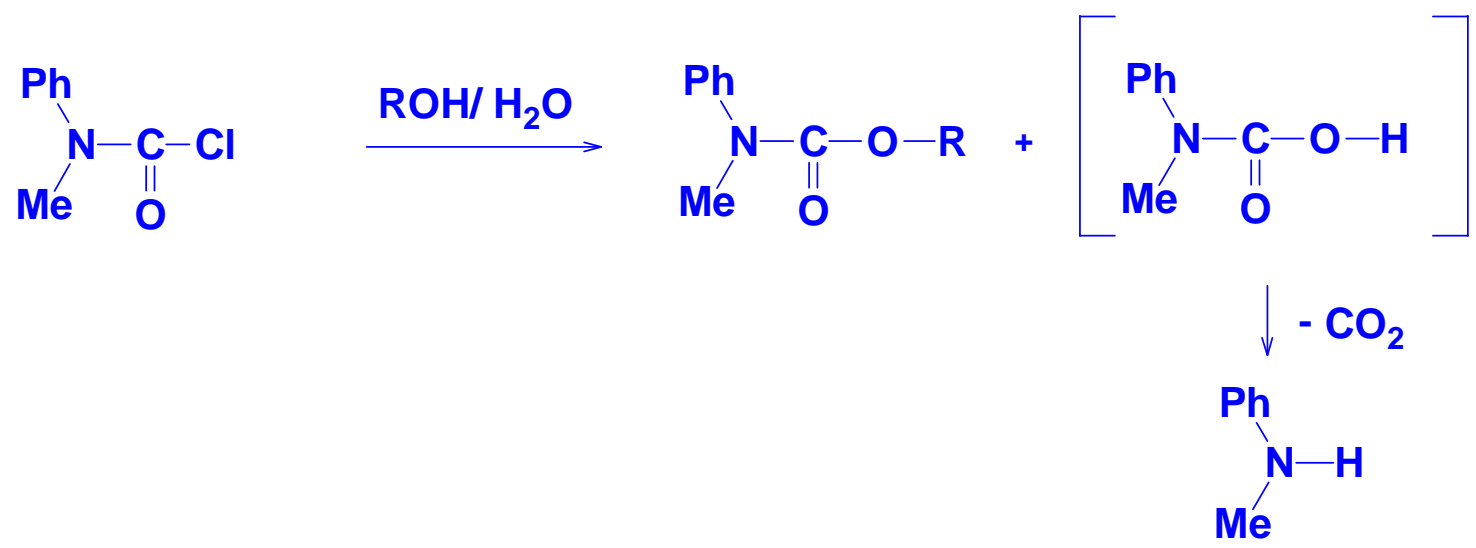

\section{Scheme 1}

For the parent compound, the previous study [29] in 19 solvents included eight TFE-containing solvents, as opposed to only three out of 32 in the more recent study. An excellent correlation of these data [36] is obtained using equation 2, with a correlation coefficient of 0.994 . This value increased only to 0.995 when equation 3 was employed with a drop in the F-test value from 1290 to 939 . The $\underline{\mathrm{h}}$ value of $0.23 \pm 0.12$ led to a probability that the $\underline{\mathrm{hI}}$ term was statistically insignificant of 0.068 , lower than the earlier value of 0.514 (associated with an $\underline{\mathrm{h}}$ value of $0.12 \pm 0.20$ ) but again giving very little support for the inclusion of an $\underline{\mathrm{hI}}$ term within these solvolyses. In the original study [36], although data for 32 solvents were available only 16 were included in the correlation and values of 0.53 for $\underline{\ell}, 0.60$ for $\underline{\mathrm{m}}$, and 0.36 for $\underline{\mathrm{h}}$ were reported, with an equation 3 multiple correlation coefficient of 0.999 . Unfortunately, no further indications of the goodness-of-fit were reported and equation 2 was not tested for any of the three substrates to see as to whether it represented an adequate correlation equation for the solvolyses.

The solvolyses of the p-chloroderivative includes, in addition to the three TFE-water mixtures, two TFE-ethanol mixtures, which were not, however, included in the equation 3 correlation. Indeed, the correlation which was presented with the use of equation 3 included only 15 of the 32 measured specific rates. Values were obtained of 0.50 for $\underline{\ell}, 0.58$ for $\underline{\mathrm{m}}$, and 0.44 for $\underline{\mathrm{h}}$, with the rather high $\underline{\mathrm{h}}$ 
value suggesting the possibility of a meaningful contribution from the $\underline{\mathrm{hI}}$ term. In Table 1 is presented our present correlation, using all 32 solvents [37]. The $\underline{\ell}$ and $\underline{m}$ values are only modestly changed from the earlier values, as obtained with use of equation 3 , but the $\underline{h}$ values falls to $0.11 \pm 0.20$ (probability that the $\underline{\mathrm{hI}}$ term is insignificant of 0.59 ). Also the correlation coefficient, as expressed to three significant figures, is unchanged on going from equation 2 to equation 3.

The solvolyses of the p-nitroderivative were studied in 20 solvents but only one of these (97\% TFE, $\mathrm{v} / \mathrm{v}$ ) included a fluoroalcohol component. An analysis in terms of equation 3 was not presented but when carried out it yields reasonable $\underline{\ell}$ and $\underline{\mathrm{m}}$ values, but a negative $\underline{\mathrm{h}}$ value of $-0.29 \pm 0.33$. The negative value is probably an artifact caused by the shortage of fluoroalcohol containing solvents.

The analyses of the specific rates of solvolyses for these three substrates show modest $\underline{\ell}$ and $\underline{\mathrm{m}}$ values, believed to represent nucleophilic solvation to an ionic process, with the unusually low $\underline{m}$ value for such a process resulting from internal nucleophilic assistance from the lone pair of electrons on the nitrogen. This leads to a transition state that is earlier than what would be expected for an unassisted or only weakly assisted process. The magnitude of the $\underline{h}$ values when equation 3 is applied does not support the claim [36] for a need to include the $\underline{\mathrm{hI}}$ term in the correlations. The insignificance of the $\underline{\mathrm{hI}}$ term in the solvolyses of the parent compound was previously demonstrated [29]. With the inclusion of all of the new data points [36] in the presently reported correlations and with the accompanying consideration of two derivatives giving very similar correlations, the earlier conclusion [29] is considerably strengthened.

\subsection{Solvolyses of $N$, $N$-Diphenylcarbamoyl Chloride}

In a thorough study of the kinetics of these reactions [27], correlation analyses were carried out for 36 solvents at $62.5^{\circ} \mathrm{C}$. The reactions are shown in Scheme 2. Using equation 2, values for $\underline{\ell}$ of 0.23 and for $\underline{\mathrm{m}}$ of 0.58 were obtained.

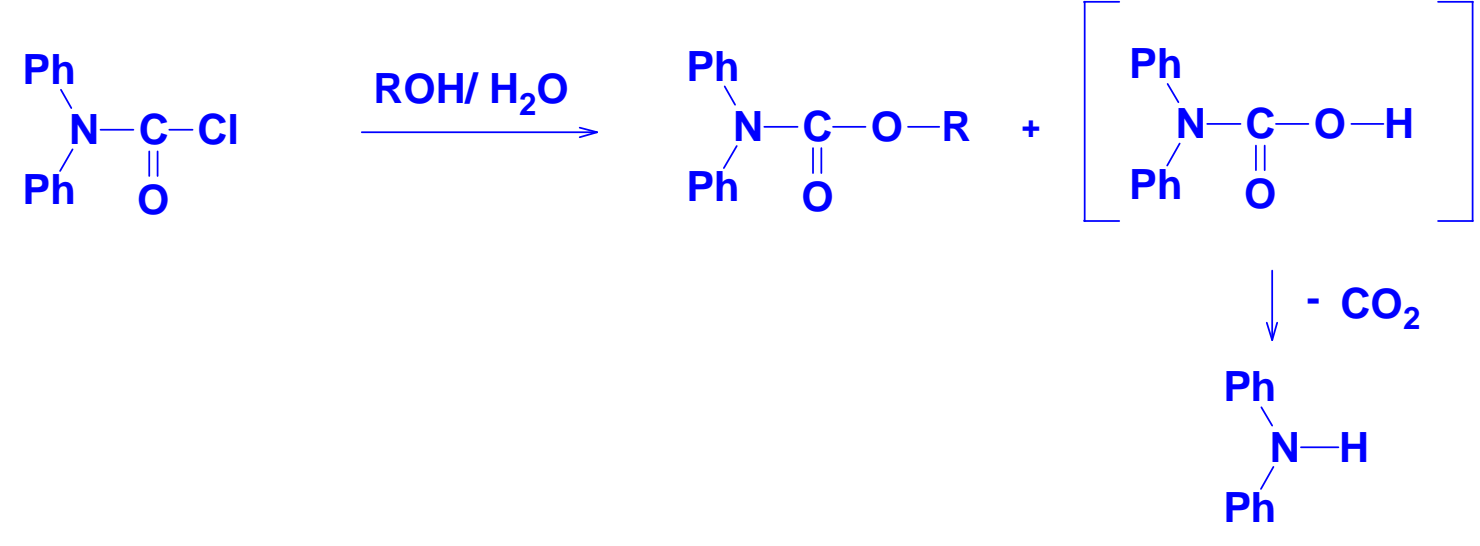

\section{Scheme 2}

The $\underline{\ell}$ value was lower than for the solvolyses of the $\underline{N}$-aryl-N-methylcarbamoyl chlorides [29]. In the present correlations, we also include a treatment using equation 3. This allows a consideration of whether treatments using the Grunwald-Winstein equation approach can give evidence supporting the claim on an extensive transfer of charge to the phenyl rings [32]. Since I values are not available for the three aqueous-acetonitrile solvents used in the study, the present correlations (Table 1) are with the use of 33 solvents. Using equation 2 , the $\underline{\ell}$ and $\underline{m}$ values were unchanged from those obtained with the full 
36 solvents. With use of equation 3 , the $\underline{h}$ value of $0.55 \pm 0.19$ was associated with the probability that the hI was statistically insignificant of only 0.007 (Figure 1). Further, on incorporation of the hI term, the $\underline{\ell}$ and $\underline{m}$ values of 0.40 and 0.67 , respectively, became comparable with those observed for the solvolyses of $\mathrm{N}$-aryl-N-methylcarbamoyl chloride substrates (Table 1). Consistent with the claims by Liu [32], it does appear that there is moderately convincing evidence for the need to incorporate the $\underline{\mathrm{hI}}$ term. Just as in the comparison of the formation of benzyl and benzyhydryl (diphenylmethyl) cations $[13,17]$, it does appear that, with carbamoyl cation formation, two aromatic rings lead to a larger $\underline{h}$ value then when only one aromatic ring is present, such that, if the values are rather low, it can lead to it becoming appreciably larger than the associated standard error.

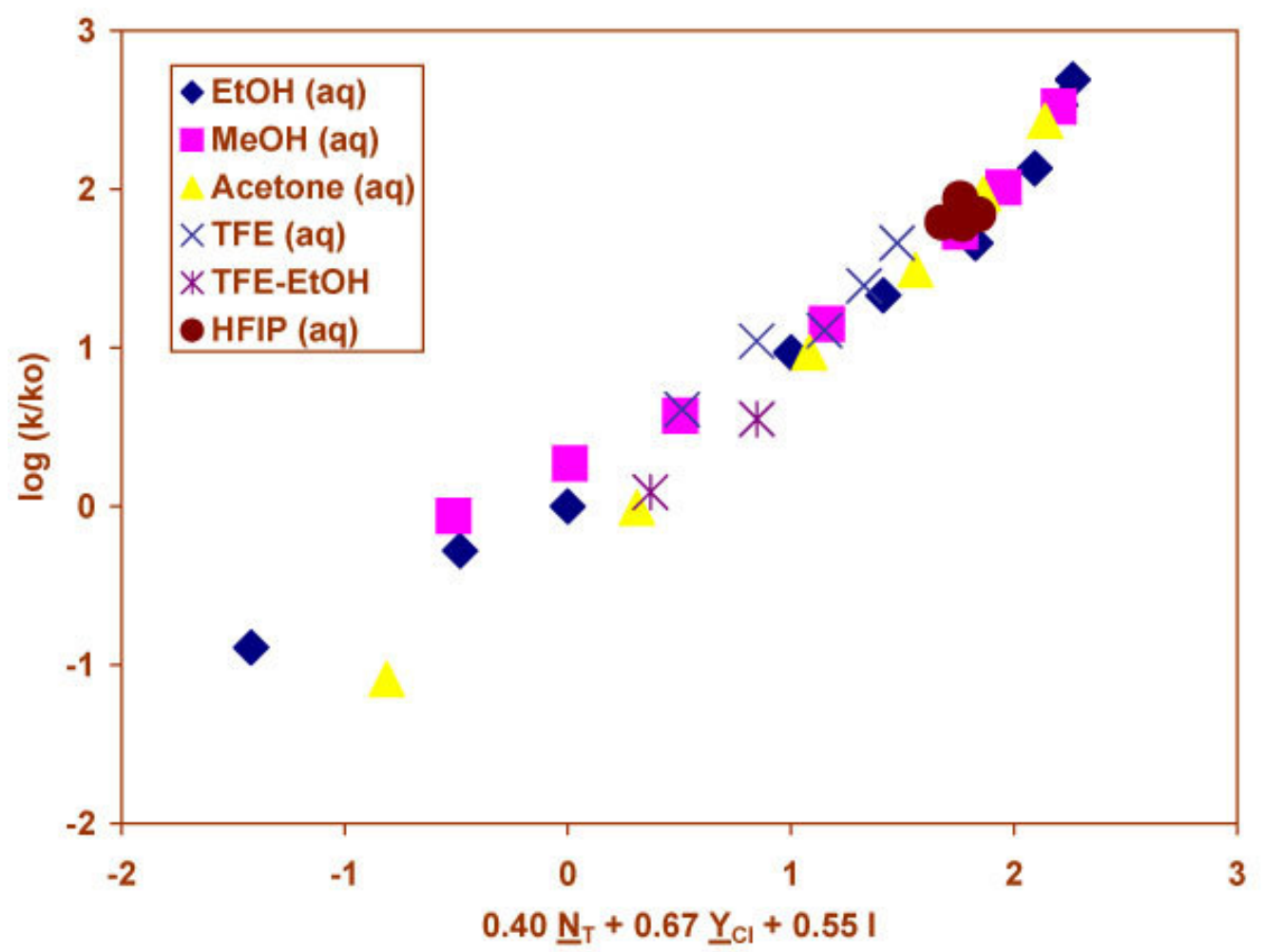

Figure 1. The plot of $\log \left(\underline{\mathrm{k}}_{\mathrm{k}}\right)$ vs. $\left(0.40 \underline{\mathrm{N}}_{\mathrm{T}}+0.67 \underline{\mathrm{Y}}_{\mathrm{Cl}}+0.55 \underline{\mathrm{I}}\right)$ for the solvolyses of $\underline{\mathrm{N}}, \underline{\mathrm{N}}-$ diphenylcarbamoyl chloride in pure and binary solvents at $62.5^{\circ} \mathrm{C}$. 
Table 1. Correlations ${ }^{\underline{a}}$ of the specific rates of solvolyses of three $\underline{N}$-methyl- $\underline{N}$-arylcarbamoyl chlorides and $\underline{\mathrm{N}}, \underline{\mathrm{N}}$-diphenylcarbamoyl chloride using the original and extended forms of the Grunwald-Winstein equation.

\begin{tabular}{|c|c|c|c|c|c|c|c|c|}
\hline Substrate & $\mathrm{T}^{\circ} \mathrm{C}$ & $\underline{n^{b}}$ & $\underline{\ell}^{\mathrm{c}}$ & $\underline{\mathrm{m}}^{\mathrm{c}}$ & $\underline{\mathrm{h}}^{\mathrm{c}}$ & $\underline{c^{c}}$ & $\underline{\mathrm{R}^{\mathrm{d}}}$ & $\mathrm{F}^{\mathrm{e}}$ \\
\hline $\mathrm{MePhNCOCl}^{\mathrm{f}}$ & 25.0 & $\overline{32}$ & & $0.55 \pm 0.03$ & & $-0.10 \pm 0.08$ & $0 . \overline{965}$ & 408 \\
\hline & & & & $0.51 \pm 0.03$ & $\begin{array}{c}-0.62 \pm 0.20 \\
(0.004)^{\mathrm{g}}\end{array}$ & $-0.08 \pm 0.07$ & 0.974 & 269 \\
\hline & & & $0.44 \pm 0.04$ & $0.68 \pm 0.02$ & & $0.01 \pm 0.03$ & 0.994 & 1290 \\
\hline & & & $0.50 \pm 0.05$ & $0.71 \pm 0.02$ & $\begin{array}{c}0.23 \pm 0.12 \\
(0.068)^{\mathrm{g}}\end{array}$ & $0.02 \pm 0.03$ & 0.995 & 939 \\
\hline $\mathrm{Me}(4-$ & 25.0 & 32 & & $0.53 \pm 0.04$ & & $0.02 \pm 0.10$ & 0.936 & 213 \\
\hline & & & & $0.46 \pm 0.04$ & $-0.73 \pm 0.19$ & $0.13 \pm 0.09$ & 0.958 & 163 \\
\hline & & & $0.44 \pm 0.06$ & $0.66 \pm 0.03$ & & $0.13 \pm 0.06$ & 0.980 & 347 \\
\hline & & & $0.47 \pm 0.09$ & $0.68 \pm 0.05$ & $\begin{array}{c}0.11 \pm 0.20 \\
(0.591)^{\mathrm{g}}\end{array}$ & $0.13 \pm 0.06$ & 0.980 & 226 \\
\hline $\mathrm{Me}\left(4-\mathrm{NO}_{2} \mathrm{C}_{6} \mathrm{H}_{4}\right)$ & 25.0 & 20 & & $0.55 \pm 0.09$ & & $-1.86 \pm 0.28$ & 0.831 & 40 \\
\hline & & & & $0.39 \pm 0.07$ & $-1.56 \pm 0.32$ & $-1.71 \pm 0.19$ & 0.934 & 58 \\
\hline & & & $0.58 \pm 0.06$ & $0.69 \pm 0.04$ & & $-1.68 \pm 0.12$ & 0.974 & 154 \\
\hline & & & $0.51 \pm 0.10$ & $0.64 \pm 0.07$ & $\begin{array}{c}-0.29 \pm 0.33 \\
(0.395)^{\mathrm{g}}\end{array}$ & $-1.68 \pm 0.12$ & 0.975 & 102 \\
\hline $\mathrm{Ph}_{2} \mathrm{NCOCl}^{\underline{h}}$ & 62.5 & 33 & & $0.48 \pm 0.03$ & & $0.00 \pm 0.09$ & 0.942 & 249 \\
\hline & & & & $0.47 \pm 0.03$ & $\begin{array}{c}-0.33 \pm 0.15 \\
(0.034)^{\mathrm{g}}\end{array}$ & $0.04 \pm 0.09$ & 0.951 & 140 \\
\hline & & & $0.23 \pm 0.04$ & $0.58 \pm 0.03$ & & $0.08 \pm 0.07$ & 0.969 & 234 \\
\hline & & & $0.40 \pm 0.07$ & $0.67 \pm 0.04$ & $\begin{array}{c}0.55 \pm 0.19 \\
(0.007)^{\mathrm{g}}\end{array}$ & $0.07 \pm 0.06$ & 0.976 & 197 \\
\hline $\mathrm{MePhNCOCl}^{\mathrm{i}}$ & 62.5 & 19 & & $0.30 \pm 0.04$ & & $-0.16 \pm 0.07$ & 0.869 & 52 \\
\hline & & & & $0.31 \pm 0.04$ & $\begin{array}{c}-0.31 \pm 0.25 \\
(0.216)^{\mathrm{g}}\end{array}$ & $-0.10 \pm 0.08$ & 0.882 & 28 \\
\hline & & & $0.40 \pm 0.08$ & $0.51 \pm 0.05$ & & $0.01 \pm 0.06$ & 0.948 & 70 \\
\hline & & & $0.43 \pm 0.10$ & $0.53 \pm 0.06$ & $\begin{array}{c}0.13 \pm 0.20 \\
(0.514)^{\mathrm{g}}\end{array}$ & $0.00 \pm 0.06$ & 0.949 & 45 \\
\hline
\end{tabular}

${ }^{a}$ The equation used can be deduced from the sensitivity parameters quoted; for each substrate, the entries involve a sequence of equations: $1,4,2,3 .{ }^{\underline{b}}$ Number of data points. ${ }^{\stackrel{c}{W} W i t h}$ associated standard error [large values for third substrate because only $\log \underline{k}$ plotted (no $\underline{\mathrm{k}}_{\mathrm{o}}$ value available)]. ${ }^{\mathrm{d}}$ Correlation coefficient. ${ }^{\mathrm{e}} \mathrm{F}$-test value. ${ }^{\mathrm{f}}$ Specific rates from ref. $36 .{ }^{\mathrm{g}}$ Probability that the $\underline{\mathrm{hI}}$ term is not statistically significant, presented when greater than $0.001 .{ }^{\mathrm{h}}$ Specific rates from ref. $27 .{ }^{\mathrm{i}}$ Specific rates from ref. 29. 


\subsection{Solvolyses of Phenyl and p-Methoxyphenyl Chloroformates}

For phenyl chloroformate solvolysis (Scheme 3), the correlation in terms of equation 2 represented our first attempt to apply the equation to a situation involving solvolytic attack other than at an $\mathrm{sp}^{3}$ hybridized carbon atom [21].

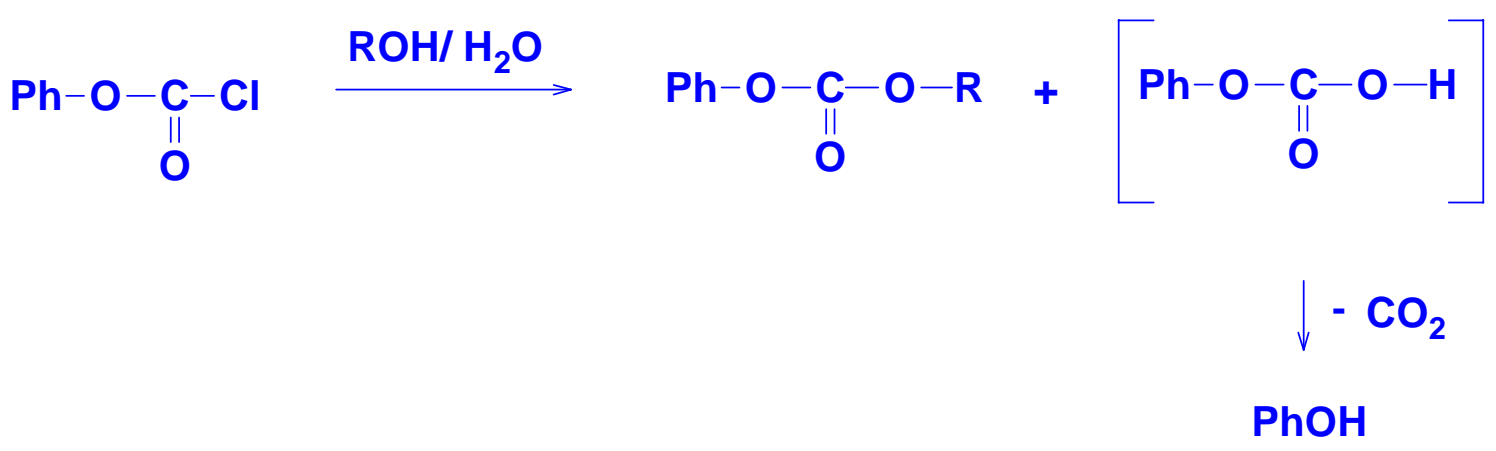

\section{Scheme 3}

Despite a claim that the methanolysis of phenyl chloroformate involves a concerted displacement mechanism [38], there is considerable evidence that these solvolyses are with the addition step of an addition-elimination sequence being rate-determining [21, 39]. The $\underline{\ell}$ and $\underline{\mathrm{m}}$ values of 1.68 and 0.57 observed for the phenyl chloroformate were considered to be important values, which could be used as standards for this type of solvolytic process. The initial correlation involved 21 solvents.

Table 2. Specific rates of solvolysis ( $\underline{\mathrm{k}}$ ) for the solvolysis of phenyl chloroformate in several binary solvents at $25.0^{\circ} \mathrm{C}$ and the solvent nucleophilicity $\left(\underline{\mathrm{N}}_{\mathrm{T}}\right)$, solvent ionizing power $\left(\underline{\mathrm{Y}}_{\mathrm{Cl}}\right)$, and aromatic ring parameter (I) values for the solvents.

\begin{tabular}{|c|c|c|c|c|}
\hline Solvent $(\%)^{a}$ & $10^{4} \underline{k}\left(s^{-1}\right)^{\underline{b}}$ & $\underline{\mathbf{N}}_{T^{\mathbf{c}}}$ & $\underline{\mathbf{Y}}_{\mathrm{Cl}^{\mathbf{d}}}$ & $\underline{\mathbf{I}}^{\mathrm{e}}$ \\
\hline $90 \%$ Acetone $(\mathrm{v} / \mathrm{v})$ & $2.38 \pm 0.14$ & -0.35 & -2.22 & -0.17 \\
\hline $80 \%$ TFE (w/w) & $0.702 \pm 0.028$ & -2.22 & 2.90 & 0.28 \\
\hline $70 \%$ TFE (w/w) & $1.74 \pm 0.13$ & -1.98 & 2.96 & 0.25 \\
\hline $50 \%$ TFE (w/w) & $6.35 \pm 0.30$ & -1.73 & 3.16 & 0.09 \\
\hline $60 \mathrm{~T}-40 \mathrm{E}(\mathrm{v} / \mathrm{v})$ & $1.99 \pm 0.05^{\mathrm{f}}$ & -0.94 & 0.63 & 0.59 \\
\hline $50 \mathrm{~T}-50 \mathrm{E}(\mathrm{v} / \mathrm{v})$ & $4.21 \pm 0.17$ & -0.64 & 0.16 & 0.51 \\
\hline $40 \mathrm{~T}-60 \mathrm{E}(\mathrm{v} / \mathrm{v})$ & $5.77 \pm 0.19$ & -0.34 & -0.48 & 0.43 \\
\hline $20 \mathrm{~T}-80 \mathrm{E}(\mathrm{v} / \mathrm{v})$ & $16.9 \pm 0.9$ & 0.08 & -1.42 & 0.31 \\
\hline $97 \%$ HFIP (w/w) & $1.48( \pm 0.20) \times 10^{-4}$ & -5.26 & 5.17 & 0.73 \\
\hline
\end{tabular}

${ }^{\mathrm{a}}$ Volume-volume $(\mathrm{v} / \mathrm{v})$ basis at $25.0^{\circ} \mathrm{C}$ or weight-weight $(\mathrm{w} / \mathrm{w})$ basis, as described; other component water, except for TFE-ethanol (T-E) solvents. ${ }^{\underline{b}}$ with associated standard deviation. ${ }^{\mathrm{c}}$ From ref. $33 .{ }^{\mathrm{d}}$ From refs. 3 and $34 .{ }^{\mathrm{e}}$ From ref. $10 .{ }^{\mathrm{f}}$ Previous value [21] of $1.75 \pm$ 0.05 . 
We have determined eight additional specific rates (Table 2) and the study by Koo, Lee and coworkers [39] allows 20 specific rate determinations in additional solvents to be included. The full 49 determinations, at $25.0^{\circ} \mathrm{C}$, now available are used in the correlations using equations 1,2 , and 3 (Table $3)$. With use of equation 2 , values for $\underline{\ell}$ and $\underline{m}$ of 1.66 and 0.56 , respectively, are in excellent agreement with those obtained earlier [21] with only 21 determinations. This indicates that the correlation is robust. The earlier [21] multiple correlation coefficient of 0.973 improves to 0.980 with the 49 data points. On incorporation of the $\underline{\mathrm{hI}}$ term (equation 3), the correlation coefficient increases only from 0.980 to 0.982 and the $\underline{h}$ values of $0.35 \pm 0.19$ is associated with a probability that the term is statistically insignificant of 0.068 . The very robust correlation (Figure 2) using equation 2 suggests that this is the best equation to use in the correlation, and the use of this correlation as a standard for rate-determining nucleophilic addition [21] is given strong support.

The study by Koo, Lee and coworkers was only in a wide range of mixtures of water with methanol, ethanol, and acetone and the analyses carried out were in terms of third-order rate coefficients, consistent with general-base catalysis to the substitution process. The present application of equations 2 and 3 was meaningful only because of the availability of fluoroalcohol-containing solvents. The important additional data was from Table 2 and the earlier publication [21].

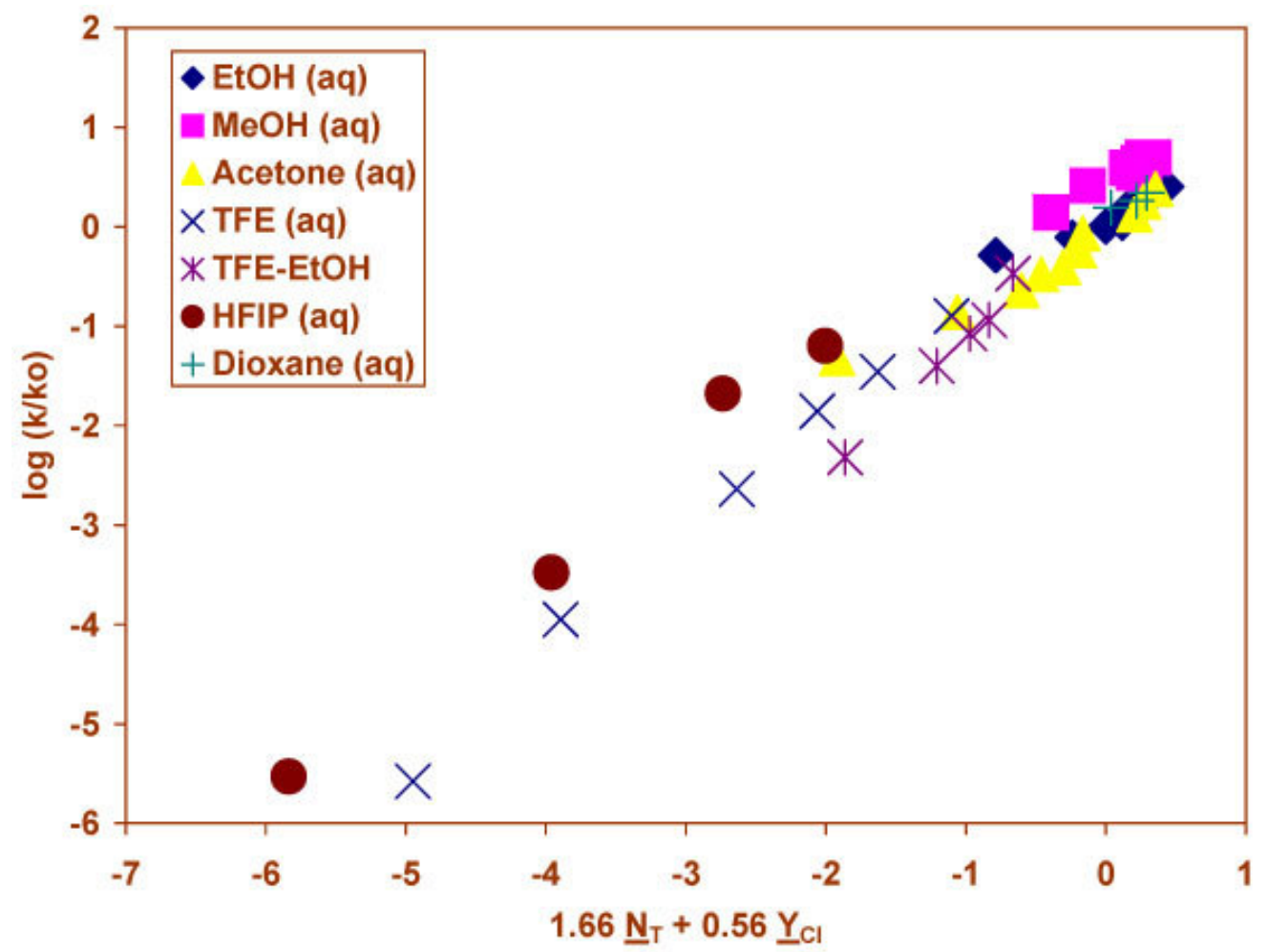

Figure 2. The plot of $\log \left(\underline{\mathrm{k}} / \underline{\mathrm{k}}_{\mathrm{o}}\right)$ vs. $\left(1.66 \underline{\mathrm{N}}_{\mathrm{T}}+0.56 \underline{\mathrm{Y}}_{\mathrm{Cl}}\right)$ for the solvolyses of phenyl chloroformate in pure and binary solvents at $25.0^{\circ} \mathrm{C}$. 
Table 3. Correlation ${ }^{\mathrm{a}}$ of the rates of solvolysis of phenyl chloroformate, its $\mathrm{p}$-methoxy derivative, and the thiono and dithio derivatives, at $25.0^{\circ} \mathrm{C}$, using the original and extended forms of the Grunwald-

Winstein equation.

\begin{tabular}{|c|c|c|c|c|c|c|c|}
\hline Substrate & $\underline{\mathrm{n}}^{\mathrm{b}}$ & $\underline{\ell^{c}}$ & $\underline{\mathrm{m}}^{\mathrm{c}}$ & $\underline{\mathrm{h}^{\mathrm{c}}}$ & $\underline{c^{c}}$ & $\underline{\mathrm{R}^{\mathrm{d}}}$ & $\underline{\mathrm{F}}^{\mathrm{e}}$ \\
\hline \multirow[t]{4}{*}{$\mathrm{PhOCOCl}^{\mathrm{f}}$} & $49^{\mathrm{g}}$ & & $-0.07 \pm 0.11$ & & $-0.46 \pm 0.31$ & 0.093 & 0.4 \\
\hline & & $1.66 \pm 0.05$ & $0.56 \pm 0.03$ & & $0.15 \pm 0.07$ & 0.980 & 568 \\
\hline & & $1.77 \pm 0.08$ & $0.61 \pm 0.04$ & $0.35 \pm 0.19$ & $0.16 \pm 0.06$ & 0.982 & 400 \\
\hline & $21^{\mathrm{i}}$ & $1.68 \pm 0.10$ & $0.57 \pm 0.06$ & & $0.12 \pm 0.13$ & 0.973 & 159 \\
\hline \multirow{3}{*}{$\begin{array}{l}4-\mathrm{MeO}^{\mathrm{C}} \mathrm{H}_{4} \mathrm{OCOCl} \\
\end{array}$} & $31^{\mathrm{g}}$ & & $0.06 \pm 0.07$ & & $-0.02 \pm 0.21$ & 0.153 & 0.7 \\
\hline & & $1.46 \pm 0.08$ & $0.53 \pm 0.03$ & & $0.18 \pm 0.06$ & 0.964 & 182 \\
\hline & & $1.75 \pm 0.07$ & $0.66 \pm 0.03$ & $0.85 \pm 0.15$ & $0.22 \pm 0.04$ & 0.984 & 274 \\
\hline \multirow{10}{*}{$\mathrm{PhOCSCl}^{\mathrm{k}}$} & $40^{\mathrm{g}}$ & & $0.16 \pm 0.06$ & & $-0.23 \pm 0.18$ & 0.393 & 6.9 \\
\hline & & $0.49 \pm 0.10$ & $0.37 \pm 0.06$ & & $-0.12 \pm 0.14$ & 0.706 & 18 \\
\hline & & $0.69 \pm 0.16$ & $0.48 \pm 0.09$ & $\begin{array}{c}0.65 \pm 0.43 \\
(0.135)^{\underline{h}}\end{array}$ & $-0.10 \pm 0.14$ & 0.727 & 13 \\
\hline & $9^{\underline{\ell}}$ & & $-0.25 \pm 0.23$ & & $-0.34 \pm 0.29$ & 0.376 & 1.2 \\
\hline & & $1.88 \pm 0.28$ & $0.56 \pm 0.15$ & & $0.38 \pm 0.15$ & 0.950 & 28 \\
\hline & $18^{\underline{\mathrm{m}}}$ & & $0.90 \pm 0.18$ & & $-3.14 \pm 0.68$ & 0.784 & 26 \\
\hline & & $0.34 \pm 0.05$ & $0.93 \pm 0.09$ & & $-2.54 \pm 0.34$ & 0.955 & 77 \\
\hline & & $0.50 \pm 0.12$ & $1.01 \pm 0.10$ & $\begin{array}{c}0.51 \pm 0.36 \\
(0.181)^{\underline{h}}\end{array}$ & $-2.53 \pm 0.34$ & 0.961 & 56 \\
\hline & $12^{\mathrm{n}}$ & & $0.93 \pm 0.15$ & & $-3.50 \pm 0.56$ & 0.898 & 41 \\
\hline & & $0.26 \pm 0.04$ & $0.94 \pm 0.07$ & & $-2.88 \pm 0.29$ & 0.980 & 107 \\
\hline \multirow[t]{3}{*}{$\mathrm{PhSCSCl}^{\circ}$} & $31^{\mathrm{g}}$ & & $0.66 \pm 0.06$ & & $-0.05 \pm 0.12$ & 0.896 & 118 \\
\hline & & $0.69 \pm 0.05$ & $0.95 \pm 0.03$ & & $0.18 \pm 0.05$ & 0.987 & 521 \\
\hline & & $0.80 \pm 0.06$ & $1.02 \pm 0.04$ & $\begin{array}{c}0.42 \pm 0.15 \\
(0.009)^{\mathrm{h}}\end{array}$ & $0.16 \pm 0.04$ & 0.990 & 485 \\
\hline
\end{tabular}

${ }^{a}$ The equation used can be deduced from the sensitivity parameters quoted. ${ }^{\mathrm{b}}$ Number of data points. ${ }^{\mathrm{c}}$ With associated standard error. ${ }^{\mathrm{d}}$ Correlation coefficient. ${ }^{\mathrm{e}}$ F-test value. ${ }^{\mathrm{f}}$ Specific rates from Table 2 and refs. 21 and 39. ${ }^{\mathrm{g}}$ All available. ${ }^{\mathrm{h}}$ Probability that the $\underline{\mathrm{hI}}$ term is not statistically significant, presented when greater than 0.001. ${ }^{\mathrm{i}}$ Values from ref. 21, using all of the data there available. ${ }^{\mathrm{i}}$ Data from refs. 21 and $39 .{ }^{\mathrm{k}}$ Data from refs. 42 and $43 .{ }^{1}$ Using data in $100-80 \%$ ethanol, $100-80 \%$ methanol, $80 \%$ acetone, $80 \mathrm{~T}-20 \mathrm{E}$, and $60 \mathrm{~T}-40 \mathrm{E} .{ }^{\mathrm{m}}$ Using data in water, 30-10\% ethanol, 30-10\% methanol, 30-10\% acetone, and all TFE-water and HFIP-water mixtures. ${ }^{n}$ Using water, $10 \%$ ethanol, $10 \%$ methanol, $10 \%$ acetone, and all TFE-water and HFIP-water mixtures. (insufficient data to justify correlation with addition of the $\underline{\mathrm{hI}}$ term). ${ }^{\circ}$ Data from refs. 42 and 46.

The data used in the analysis presented in Table 3 for solvolyses of p-methoxyphenyl chloroformate are primarily from the Korean work [39], with 29 determinations in aqueous methanol, ethanol, and acetone combined with just two values available [21] for fluoroalcohol-containing solvents; (90 and $50 \%$ HFIP). This is not a very satisfactory mix of solvents and values from the correlations (Table 3 ) must be treated with caution. The equation 2 values of 1.46 for $\underline{\ell}$ and 0.53 for $\underline{\mathrm{m}}$ rose to 1.75 and 0.66 , respectively, when equation 3 is applied, with an $\underline{h}$ value of $0.85 \pm 0.15$. While this would seem to indicate that the $\underline{\mathrm{hI}}$ term is significant, we believe that further data points for solvolyses in the fluoroalcohol-containing solvents are needed, for incorporation into the correlation, before the significance, or otherwise, of the $\underline{\mathrm{hI}}$ term can be considered as established. 


\subsection{Solvolyses of Phenyl Chlorothionoformate and Chlorodithioformate}

Queen studied the hydrolysis of phenyl chlorothionoformate and, from a comparison with the rate for the methyl, ethyl, and isopropyl esters, he concluded that an $S_{N} 1$ pathway was followed [40]. In contrast, in 65\% acetone Csunderlick et al [41] found evidence for a bimolecular mechanism for the solvolyses. A previous treatment in terms of the Grunwald-Winstein equation [42] confirmed that two mechanisms are indeed involved and in aqueous TFE or aqueous HFIP an ionization pathway dominates $(\underline{\ell}=0.43 ; \underline{m}=1.19)$. In ethanol or methanol or in mixtures of ethanol, methanol or acetone with water, containing at least $60 \%$ of the organic component, a bimolecular pathway is followed $(\underline{\ell}=$ $1.53 ; \underline{\mathrm{m}}=0.36)$.

We are revisiting these solvolyses (Scheme 4) because of a more recent report [43] which assumes a unit mechanism over the full range of water-ethanol, water-methanol, and water-acetone compositions, including the determination in pure water. Also the mechanism was believed to be a concerted $\mathrm{S}_{\mathrm{N}} 2$ process. Most surprising was the belief that a large contribution from the $\underline{\mathrm{hI}}$ term was involved. Although specific rate data for 29 solvent systems were reported, only 13 were included in analyses against $\underline{Y}_{\mathrm{Cl}}$ plus $\underline{\mathrm{I}}$ and in analysis in terms of equation 3 . These two analyses led to very high $\underline{\mathrm{h}}$ values of 2.93 and 2.64, respectively. In the absence of data for fluoroalcohol-containing solvents, multicollinearity between the three scales will be a major problem, especially with only a limited number of data points.

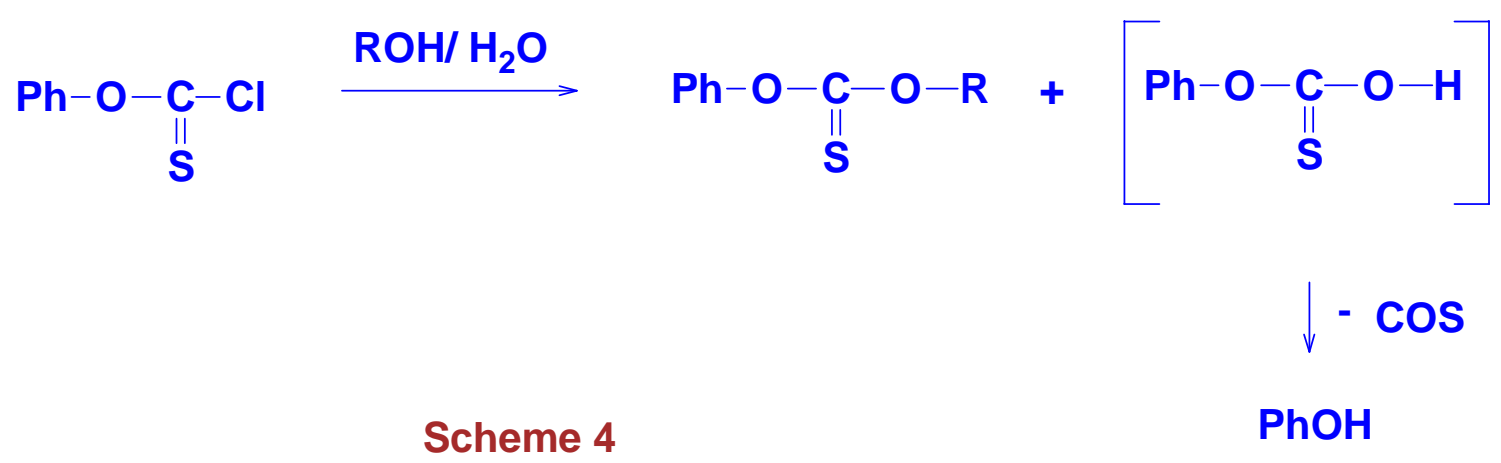

There are, in total, data points available [42, 43] for 40 solvent compositions, including ten containing fluoroalcohol. Using equation 3 for all 40 data points, the correlation using equation 3 is poor, with a correlation coefficient of only 0.727 and an $\underline{\ell}$ value of 0.69 , $\underline{\mathrm{m}}$ value of 0.48 , and $\underline{\mathrm{h}}$ value of $0.65 \pm 0.43$, with a 0.135 probability that the $\underline{\mathrm{hI}}$ term is statistically insignificant (Table 3 ). In view of the evidence from our laboratory [42] and other laboratories [40, 41] for a duality of mechanism, the poor correlation is not surprising. For the nine solvents least favoring ionization values are obtained of 1.88 for $\underline{\ell}$ and 0.56 for $\underline{m}$ when equation 2 is applied, values to be expected if the addition step of an addition-elimination mechanism is dominant. For 18 solvent expected to favor ionization, values from equation 3 of 0.50 for $\underline{\ell}, 1.01$ for $\underline{\mathrm{m}}$, and $0.51 \pm 0.36$ for $\underline{\mathrm{h}}(0.181$ probability that the $\underline{\mathrm{hI}}$ term is statistically insignificant) were calculated (Table 3 ). 
The changes in the kinetic deuterium solvent isotope effect with solvent [43] are also consisted with the change in mechanism. The $\mathrm{k}_{\mathrm{SOH}} / \mathrm{k}_{\mathrm{SOD}}$ value of 2.02 for methanol is consisted with a general-based catalyzed bimolecular process, which is reduced to a value of 1.91 in $50 \%$ methanol, where both mechanisms will be appreciably operating, and to 1.45 in water, where the ionization mechanism is dominant. For chloroformate esters in $\mathrm{H}_{2} \mathrm{O}$ and $\mathrm{D}_{2} \mathrm{O}$, a value of 1.79 for the phenyl ester falls to 1.25 for the isopropyl ester [44].

Queen also studied the solvolyses of phenyl chlorodithioformate (Scheme 5) and for solvolysis in $70 \%$ acetone [40, 45] concluded that the mechanism was $S_{N} 1$ in character. Our investigation [42] indicated the reaction to be unimolecular across the full range of the 14 solvents utilized $(\underline{\ell}=0.55 ; \underline{\mathrm{m}}=$ 0.84 ) including the solvolysis in $100 \%$ ethanol, which would be the most favorable for bimolecular reaction. A study by Koo, Bentley, Lee and coworkers [46] utilized 31 solvents, with 11 of these containing TFE. The 11 solvents which duplicated those of our earlier study all gave specific rates in reasonable to good agreement with the earlier values [47].

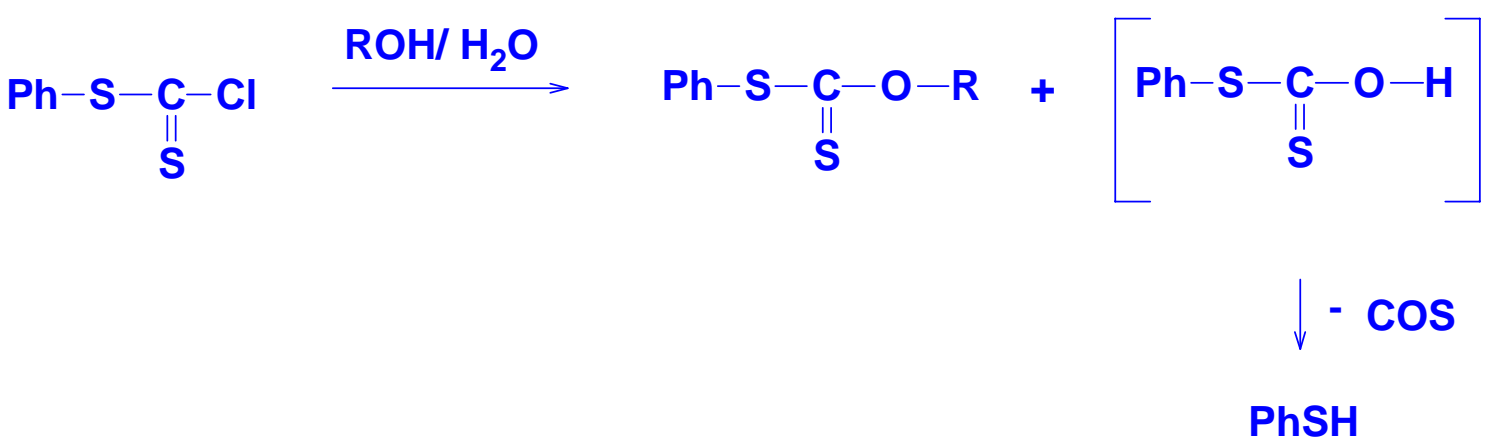

\section{Scheme 5}

With use of our original 14 solvents and 17 additional ones from the subsequent study [46], we found (Table 3), with application of equation 2, that values were obtained of 0.69 for $\underline{\ell}$ and 0.95 for $\underline{\mathrm{m}}$. With application of equation 3 (Figure 3), values of 0.80 for $\underline{\ell}, 1.02$ for $\underline{\mathrm{m}}$, and $0.42 \pm 0.15$ for $\underline{\mathrm{h}}$ (probability that the $\underline{\mathrm{hI}}$ term is not statistically significant of 0.009 ). It does appear that a contribution

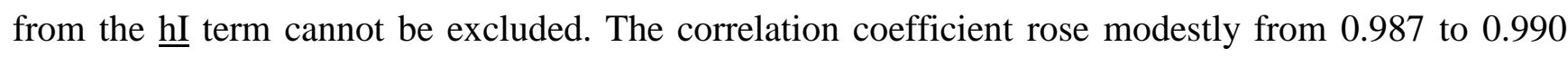
when the term was included. The value of 0.987 in its absence does indicate, however, that its inclusion is not critical. 


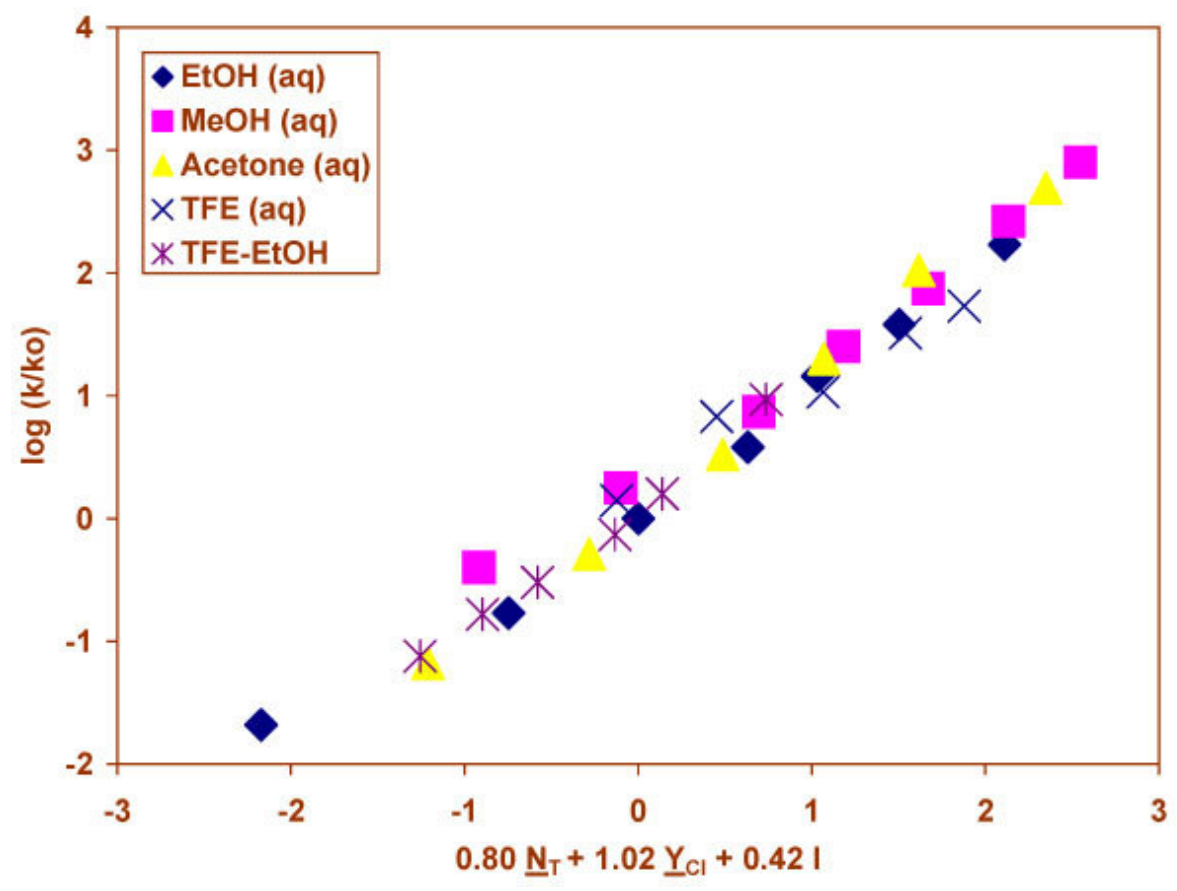

Figure 3. The plot of $\log (\mathrm{k} / \mathrm{ko})$ vs. $\left(0.80 \mathrm{~N}_{\mathrm{T}}+1.02 \mathrm{Y}_{\mathrm{Cl}}+0.42 \underline{\mathrm{I}}\right)$ for the solvolyses of phenyl chlorodithioformate in pure and binary solvents at $25.0^{\circ} \mathrm{C}$.

\section{Conclusions}

The correlations presently carried out all support the concept of an ionization mechanism with assistance from nucleophilic solvation for the solvolyses of the carbamoyl chlorides. The $\underline{\mathrm{N}}$-methyl-Narylcarbamoyl chlorides have $\underline{\ell}$ values in the range of 0.44 to 0.58 when equation 2 is applied. Application of equation 3 increases the multiple correlation coefficient only by 0.001 and it appears that the $\underline{\mathrm{hI}}$ terms is not statistically significant and, indeed, the probabilities that the $\underline{\mathrm{hI}}$ term is statistically insignificant range from 0.068 to 0.591 . The $\underline{m}$ value is rather low for an ionization mechanism ( 0.66 to 0.69 when equation 2 is applied) and this is consistent with the concept that there is considerable internal nucleophilic assistance from the lone pair on the nitrogen.

The correlations of $\underline{\mathrm{N}}, \underline{\mathrm{N}}$-diphenylcarbamoyl chloride give a lower value for $\underline{\ell}$ of 0.23 when equation 2 is applied. This is raised to 0.40 when equation 3 is applied and the $\underline{\mathrm{h}}$ value of $0.55 \pm 0.19$ is associated with a probability of only 0.007 that the $\underline{\mathrm{hI}}$ terms is statistically insignificant. It appears, consistent with the claim by Liu [32], that there is moderately strong evidence for a detectable effect when two aromatic rings, rather than one, are present.

The number of solvents now available for the correlation of the specific rates of solvolysis of phenyl chloroformate has increased dramatically from the time of our earlier correlation [21] from 21 to 49. The values for $\underline{\ell}$ and $\underline{m}$ obtained on application of equation 2 are, however, essentially unchanged, indicating the very robust character of this correlation. The values of 1.66 and 0.56 , respectively, are consistent with the previously proposed addition-elimination pathway, with the addition step being rate-determining. Application of the three-term equation 3 increases the multiple correlation coefficient only by 0.002 and the $\underline{h}$ value of $0.35 \pm 0.19$ is accompanied by a 0.068 probability that the $\underline{\mathrm{hI}}$ term is 
statistically insignificant. These solvolyses are best correlated in terms of equation 2 . The solvolyses of p-methoxyphenyl chloroformate have been correlated, but of the 31 solvents only two contain fluoroalcohol. The $\underline{\ell}$ and $\underline{m}$ values are consistent with the proposed addition-elimination pathway but additional fluoroalcohol-containing solvents are need before a high degree of confidence can be assigned to the correlations.

With phenyl chlorodithioformate, the correlations support the claim by Queen [40, 45] that the solvolyses involve an ionization mechanism. A good correlation is obtained across the full range of 31 solvents with either equation $2(\underline{\mathrm{R}}=0.987)$ or equation $3(\underline{\mathrm{R}}=0.990)$. The $\underline{\ell}$ values of 0.69 (equation 2$)$ or 0.80 (equation 3 ) are quite large indicating a high degree of nucleophilic solvation to the ionization process, with $\underline{\mathrm{m}}$ values of 0.95 (equation 2) or 1.02 (equation 3 ). The $\underline{\mathrm{h}}$ value of $0.42 \pm 0.15$ obtained with use of equation 3 has only a 0.009 probability that the $\underline{\mathrm{hI}}$ term is statistically insignificant.

The phenyl chlorothionoformate was previously [42] found to proceed by both addition-elimination and ionization mechanisms. Which pathway dominated was determined by the solvent properties, with high solvent nucleophilicity and low solvent ionizing power favoring the bimolecular pathway. A poor overall correlation ( $\underline{\mathrm{R}}=0.706$ with equation 2 applied) can be considerably improved when the 9 solvents most favorable to addition-elimination $(\underline{\mathrm{R}}=0.950)$ and the 12 solvents most favorable to ionization $(\underline{\mathrm{R}}=0.980)$ are separately correlated.

\section{Experimental Section}

Phenyl chloroformate (Aldrich, 99\%) was used as received. Solvents were purified and the kinetic runs carried out as described previously [6]. A substrate concentration of approximately $0.03 \underline{\mathrm{M}}$ was employed.

\section{Acknowledgements}

This research was supported by grant number 2 P2O RR016472-06 from the National Center for Research Resources (NCRR), a component of the National Institutes of Health (NIH). Its contents are solely the responsibility of the authors and do not necessarily represent the official views of NCRR or NIH.

\section{References and Notes}

1. Grunwald, E.; Winstein, S. The Correlation of Solvolysis Rates. J. Am. Chem. Soc. 1948, 70, 846854.

2. Bentley, T.W.; Carter G.E. The $\mathrm{S}_{\mathrm{N}} 2-\mathrm{S}_{\mathrm{N}} 1$ Spectrum. 4. Mechanism for Solvolyses of tert-Butyl Chloride: A Revised $Y$ Scale of Solvent Ionizing Power based on Solvolyses of 1-Adamantyl Chloride. J. Am. Chem. Soc. 1982, 104, 5741-5747.

3. Bentley, T.W.; Llewellyn, G. Yx Scales of Solvent Ionizing Power. Prog. Phys. Org. Chem. 1990, 17, 121-158.

4. Winstein, S.; Grunwald, E.; Jones, H.W. The Correlation of Solvolyses Rates and the Classification of Solvolysis Reactions into Mechanistic Categories. J. Am. Chem. Soc. 1951, 73, 2700-2707. 
5. Schadt, F.L.; Bentley, T.W.; Schleyer, P.v.R. The $\mathrm{S}_{\mathrm{N}} 2-\mathrm{S}_{\mathrm{N}} 1$ Spectrum. 2. Quantitative Treatments of Nucleophilic Solvent Assistance. A Scale of Solvent Nucleophilicities. J. Am. Chem. Soc. 1976, 98, 7667-7674.

6. Kevill, D.N.; Anderson, S.W. An Improved Scale of Solvent Nucleophilicity Based on the Solvolysis of the S-Methyldibenzothiophenium Ion. J. Org. Chem. 1991, 56, 1845.

7. Kaspi, J.; Rappoport, Z. Nucleophilicity and Ionizing Power in Binary Solvent Mixtures. Tetrahedron Lett. 1977, 2035-2038.

8. Kevill, D.N.; Park, B.-C.; Park, K.,-H.; D’Souza, M.J.; Yaakoubd, L.; Mlynarski, S.L.; Kyong, J.B. Rate and Product Studies in the Solvolyses of $N, N$-Dimethylsulfamoyl and 2-Propanesulfonyl Chlorides. Org. Biomol. Chem. 2006, 4, 1580-1586, and referenced therein.

9. Kevill, D.N.; Ryu, Z.H. Additional Solvent Ionizing Power Values for Binary Water 1,1,1,3,3,3,-Hexafluoro-2-propanol Solvents. Int. J. Mol. Sci. 2006, 7, 451-455.

10. Kevill, D.N.; Ismail, N.HJ.; D'Souza, M.J. Solvolysis of the (pMethoxybenzyl)dimethylsulfonium Ion. Development and Use of a Scale to Correct for Dispersion in Grunwald-Winstein Plots. J. Org. Chem. 1994, 59, 6303-6312.

11. Kevill, D.N.; D’Souza, M.J. Application of the Aromatic Ring Parameter (I) to the GrunwaldWinstein Treatment of the Specific Rates of Solvolysis of Substituted Naphthylmethyl and Anthrylmethyl Sufonates. Org. React. (Tartu). 1995, 29, 55.

12. Kevill, D.N.; D’Souza, M.J. Considerably Improved Grunwald-Winstein Correlations for Solvolyses of Several Secondary and Tertiary Benzylic Derivatives upon Inclusion of a Term Governed by the Aromatic Ring Parameter (I). J. Chem. Soc., Perkin Trans. 2. 1995, 973-980.

13. Kevill, D.N.; D’Souza, M.J. Incorporation of a Term Governed by the Aromatic Ring Parameter (I) into Grunwald-Winstein Correlations of the Solvolyses of Diarylmethyl, Naphthylmethyl and Arylmethyl Bromides. J. Chem. Res. Synop. 1996, 286-287; Miniprint, 1996, 1649.

14. Bentley, T.W.; Koo, I.S.; Norman, S.J. Distinguishing Between Solvation Effects and Mechanistic Changes. Effects Due to Differences in Solvation of Aromatic Rings and Alkyl Groups. J. Org. Chem. 1991, 56, 1604-1609.

15. Liu, K.-T; Sheu, H.-C. Solvolysis of 2-Aryl-2-Chloroadamantanes. A New Y Scale for Benzylic Chlorides. J. Org. Chem. 1991, 56, 3021-3025.

16. Liu, K.-T; Lin, Y.-S.; Duann, Y.-F. Solvent Effects on the Solvolysis of Some Secondary Tosylates. Applications of $\underline{\mathrm{Y}}_{\mathrm{BnOTs}}$ and $\mathrm{Y}_{\mathrm{xBnOTs}}$ Scales to Mechanistic Studies. J. Phys. Org. Chem. 2002, 15, 750-757.

17. Kevill, D.N.; Anderson, S.W.; Ismail, N.HJ. Correlation of the Rates of Solvolysis of the Benzhydryldimethylsulfonium Ion. Application of the Aromatic Ring Parameter. J. Org. Chem. 1996, 61, 7256-7262.

18. Kevill, D.N.; D'Souza, M.J. Application of the Aromatic Ring Parameter (I) to Solvolyses of $\beta$ Arylalkyl Toluene-p-sulfonates. J. Chem. Soc., Perkin Trans. 2. 1997, 257-264.

19. Kevill, D.N.; D'Souza, M.J. Correlation of the Rates of Solvolysis of Benzoyl Chloride and Derivatives Using Extended Forms of the Grunwald-Winstein Equation. J. Phys. Org. Chem. 2002, 15, 881-888. 
20. Kevill, D.N.; D’Souza, M.J. Correlation of the Rates of Solvolysis of Benzoyl Fluoride. J. Org. Chem. 2004, 69, 7044-7050.

21. Kevill, D.N.; D'Souza, M.J. Correlation of the Rates of Solvolysis of Phenyl Chloroformate. $J$. Chem. Soc., Perkin Trans. 2 1997, 1721-1724.

22. Kyong, J.B.; Park, B.-C.; Kim, C.-B.; Kevill, D.N. Rate and Product Studies with Benzyl and pNitrobenzyl Chloroformates Under Solvolytic Conditions. J. Org. Chem. 2000, 65, 8051-8058.

23. Kyong, J.B.; Won, H.: Kevill, D.N. Application of the Extended Grunwald-Winstein Equation to Solvolyses of $\underline{n}$-Propyl Chloroformate. Int. J. Mol. Sci. 2005, 6, 87-96.

24. D’Souza, M.J.; Boggs, M.E.; Kevill, D.N. Correlation of the Rates of Solvolysis of 2Furancarbonyl Chloride and Three Naphthoyl Chlorides. J. Phys. Org. Chem. 2006, 19, 173-178.

25. Kevill, D.N.; D'Souza, M.J. Correlation of the Rates of Solvolyses of $\underline{n}$-Octyl Fluoroformate and a Comparison with $\underline{n}$-Octyl Chloroformate Solvolyses. J. Chem. Soc., Perkin Trans. 2, 2002, 240 243.

26. Kyong, J.B.; Ryu, S.H.; Kevill, D.N. Rate and Product Studies of Solvolyses of Benzyl Fluoroformate. Int. J. Mol. Sci., 2006, 7, 186-196.

27. D’Souza, M.J.; Kevill, D.N.; Bentley, T.W.; Devaney, A.C. Kinetics and Selectivities for the Solvolyses of $\underline{\mathrm{N}}, \underline{\mathrm{N}}$-Diphenylcarbamoyl Chloride. J. Org. Chem. 1995, 60, 1632-1637.

28. Kevill, D.N.; Oldfield, A.J.; D’Souza, M.J. Correlation of the Rates of Solvolyses of N, NDimethylcarbamoyl Chloride. J. Chem. Res. Synop. 1996, 122-123.

29. Kevill, D.N.; Best, B.J.; D'Souza, M.J. Correlation of the Rates of Solvolyses of N-Methyl-Nphenylcarbamoyl Chloride. Org. React. (Tartu). 1997, 31, 55-58.

30. Kevill, D.N.; Carver, J.S. Rate and Product Studes with Dimethyl Phosphorochloridate and Dimethyl Phosphorochloridothionate Under Solvolytic Conditions. Org. Biomol. Chem. 2004, 2, 2040-2043, and references therein.

31. Kevill, D.N.; Koh, H.J. Correlation of the Rates of Solvolyses of Diphenylphosphinyl Chloride Using an Extended Form of the Grunwald-Winstein Equation. J. Phys. Org. Chem. 2007, 20, 8892

32. Liu, K.-T.; Chen, H.-I.; Lin, Y.-S.; Jin, B.-Y. Solvolysis of N, N-Diphenylcarbamoyl Chloride Revisted. Extended Positive Charge Delocalizaiton on Phenyl Rings in the Transition State and Possible Contribution of Non-Canonical Resonance Structure. J. Phys. Org. Chem. 2000, 13, 322329.

33. Kevill, D.N. Development and Uses of Scales of Solvent Nucleophilicity . In Advances in Quantitative Structure-Property Relationships, Vol 1; Charton, M., Ed.; JAI Press: Greenwich, CT, 1996; pp 81-115.

34. Kevill, D.N.; D'Souza, M.J. Additional $Y_{\mathrm{Cl}}$ Values and Correlation of the Specific Rates of Solvolysis of tert-Butyl Chloride in Terms of $N_{\mathrm{T}}$ and $Y_{\mathrm{Cl}}$ Scales. J. Chem. Res. Synop. 1993, 174175.

35. Kevill, D.N.; Anderson, S.W. Essentially Solvent-Independent Rates of Solvolysis of the 1Adamantyldimethylsulfonium Ion. Implications Regarding Nucleophilic Assistance in Solvolyses of tert-Butyl Derivatives and the $\underline{\mathrm{N}}_{\mathrm{KL}}$ Sovlent Nucleophilicity Scale. J. Am. Chem. Soc. 1986, 108, $1579-1581$. 
36. Koo, I.S.; An, S.K.; Yang, K.; Koh, H.J.; Choi, M.H.; Lee, I. Solvolyses of N-Methyl-Nphenylcarbamoyl Chlorides with Electron Acceptor Substituents in Aqueous Binary Mixtures. Bull. Korean Chem. Soc. 2001, 22, 842-846.

37. There should be no $80 \%$ acetone value, the value given within Table 1 is actually the value for $70 \%$ acetone, as can be deduced by comparison with Figure 2 of the publication.

38. Yew, K.H.; Koh, H.J.; Lee, H.W.; Lee, I. Nucleophilic Substitution Reactions of Phenyl Chloroformate. J. Chem. Soc., Perkin Trans. 2, 1995, 2263-2268.

39. Koo, I.S.; Yang, K.; Kang, K.; Lee, I. Transition-State Variation in the Solvolyses of paraSubstituted Phenyl Chloroformates in Alcohol-Water Mixtures. Bull. Korean Chem. Soc. 1998, 19, 968-972.

40. McKinnon, D.M.; Queen, A. Kinetics and Mechanism for the Hydrolysis of Chlorothionoformate and Chlorodithioformate Esters in Water and Aqueous Acetone. Can. J. Chem. 1972 50, 14011406.

41. Csunderlik, C.; Bacaloglu, R.; Ostrogovich, G. Nucleophilic Substitutions in Carbonic Acid

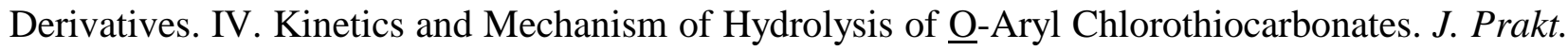
Chem (Leipzig) 1975, 317, 73.

42. Kevill, D.N.; D'Souza, M.J. Correlation of the Rates of Solvolysis of Phenyl Chlorothionoformate and Phenyl Chlorodithioformate. Can. J. Chem. 1999, 77, 1118-1122.

43. Koo, I.S.; Yang, K.; Kang, D.H.; Park, H.J.; Kang, K.; Lee, I. Transition-State Variation in the Solvolyses of Phenyl Chlorothionoformate in Alcohol-Water Mixtures. Bull. Korean Chem. Soc. 1999, 20, 577-580.

44. Queen, A. Kinetics of the Hydrolysis of the Acyl Chlorides in Pure Water. Can J. Chem. 1967, 45, 1619-1629.

45. Queen, A.; McKinnon, D.M.; Bell, A.W. The Kinetics of the Reactions of Chlorodithioformate Esters with Azide Ions in 70\% Acetone. Can J. Chem. 1976, 54, 1906-1909.

46. An, S.K.; Yang, J.S.; Cho, J.M.; Yang, K.; Lee, P.L.; Bentley, T.W.; Lee, I.; Koo, I.S. Correlation of the Rates Solvolysis of Phenyl Chlorodithioformate. Bull. Korean Chem. Soc. 2002, 23, 1445.

47. This statement is accurate after the values in TFE-water within Table 2 of ref. 46 are reduced by a factor of ten to allow for an order of magnitude error. Unfortunately, the reported values were also used in the correlations presented within the reference.

(C) 2007 by MDPI (http://www.mdpi.org). Reproduction is permitted for noncommercial purposes. 